\title{
ECHOCARDIOGRAPHY OF TRANSATRIAL EMBOLISM DURING CEMENTED AND UNCEMENTED HEMIARTHROPLASTY OF THE HIP
}

\author{
J. CHRISTIE, R. BURNETT, H. R. POTTS, A. C. H. PELL \\ From the Princess Margaret Rose Orthopaedic Hospital, Edinburgh, Scotland
}

We performed transoesophageal echocardiography on 20 patients with femoral neck fractures randomly treated with an uncemented Austin-Moore or cemented Hastings hemiarthroplasty. Cemented arthroplasty caused greater and more prolonged embolic cascades than did uncemented arthroplasty. Some emboli were more than $3 \mathrm{~cm}$ in length. In some patients the cascades were associated with pulmonary hypertension, diminished oxygen tension and saturation, and the presence of fat and marrow in aspirates from the right atrium.

J Bone Joint Surg [Br] 1994; 76-B:409-12.

Received 7 September 1993; Accepted 22 October 1993

Embolic phenomena have been detected by transoesophageal echocardiography during medullary reaming of the long bones (Wenda et al 1989; Pell et al 1993a) and during hip and knee replacement (Heinrich et al 1985; Parmet et al 1993). Hypotensive episodes (Charnley 1970; Jones 1975), hypoxaemia (Kallos 1975) and sudden death (Burgess 1970) are well-recognised complications of cemented arthroplasty. Increased pulmonary artery pressure has also been documented (Samii et al 1980; Byrick, Kay and Mullen 1987) and presumably results from vasoactive substances or medullary embolic cascades reaching the pulmonary circulation during cement insertion.

It has been reported recently (Ries et al 1993) that pulmonary shunt values increased by $28 \%$ during total hip arthroplasty when the femoral component was inserted using cement but did not change when cement was not used. Heinrich et al (1988) established that transcardiac thromboembolic phenomena, seen on echocardiography, are much reduced if a venting hole is drilled in the

J. Christic, FRCS, Consultant Orthopaedic Surgeon

R. Burnett, FRCS, Orthopaedic Senior Registrar

H. R. Potts, FRCS, Orthopaedic Senior Registrar

A. C. H. Pell, MRCP, Cardiology Research Registrar

Royal Infirmary of Edinburgh, 1 Lauriston Place, Edinburgh EH3 9YW, UK.

Correspondence should be sent to Mr J. Christie.

(1)1994 British Editorial Society of Bone and Joint Surgery

$0301-620 X / 94 / 3769 \$ 2 .(0)$ proximal medullary canal before the cement and stem are inserted. In an animal model Wheelwright et al (1993) showed that washing out the medullary canal with a water-pick reduced fat embolism and diminished the adverse pulmonary effects of cemented knee replacement.

We have studied the echogenic cascades detected during the insertion of cemented and uncemented femoral prostheses to establish whether the insertion of cement is specifically associated with more severe thromboembolism.

\section{PATIENTS AND METHODS}

We studied 20 patients with femoral neck fractures randomly allocated to treatment with an uncemented Austin-Moore hemiarthroplasty (Howmedica International Ltd, Park Royal, London, UK) or a cemented Hastings bipolar prosthesis (De Puy International Ltd, Leeds, UK). Cement was inserted using thumb pressure, with a venting catheter and a plastic plug in the femoral canal.

During the operations the heart was monitored by a $5 \mathrm{MHz}$ biplane echocardiography probe (Hewlett Packard, Wokingham, Berkshire, UK) positioned in the patient's oesophagus, which was removed immediately before the reversal of anaesthesia. The images were recorded on VHS video tape and analysed by an observer (ACHP) who was unaware of the type of implant used. During the operations we monitored the heart rate, blood pressure, arterial oxygen saturation and end-tidal $\mathrm{CO}_{2}$. When the patient's consent could be obtained a central venous catheter was inserted into the right atrium and $10 \mathrm{ml}$ of blood were taken before the operation and again when embolic material was detected within the heart chambers. The blood was analysed for fat content using the method described by Gurd (1970). The postoperative $\mathrm{PaO}_{2}$ was measured on the first and second postoperative day or until it returned to normal.

\section{RESULTS}

Several echogenic patterns were observed as follows:

Grade I. A few fine emboli (Fig. 1a).

Grade II. A cascade of many fine emboli (Figs $1 \mathrm{~b}$ and 1c). 


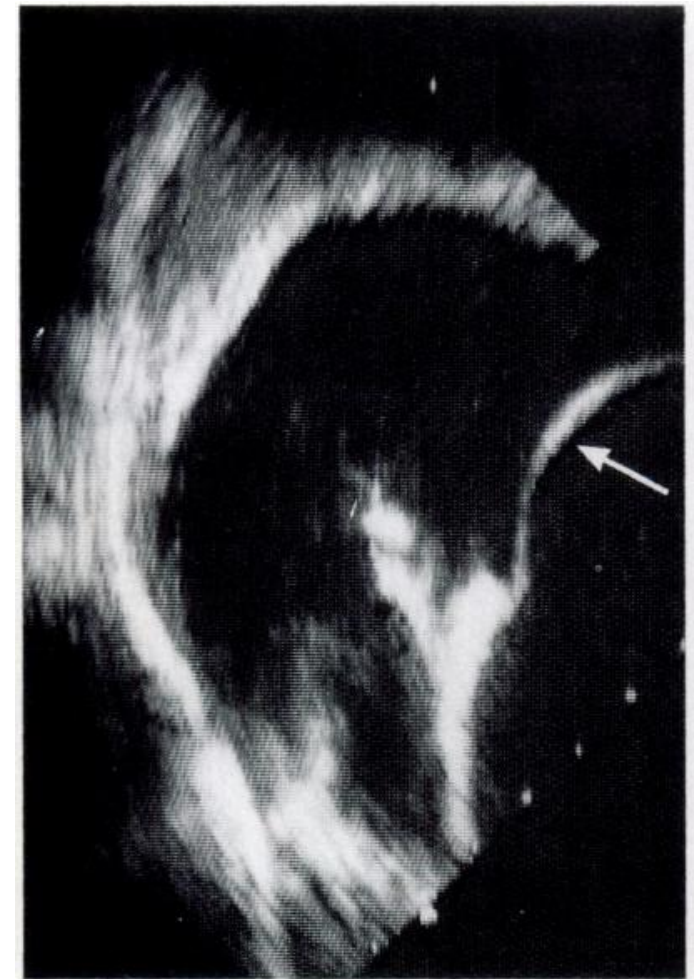

Fig. 1a

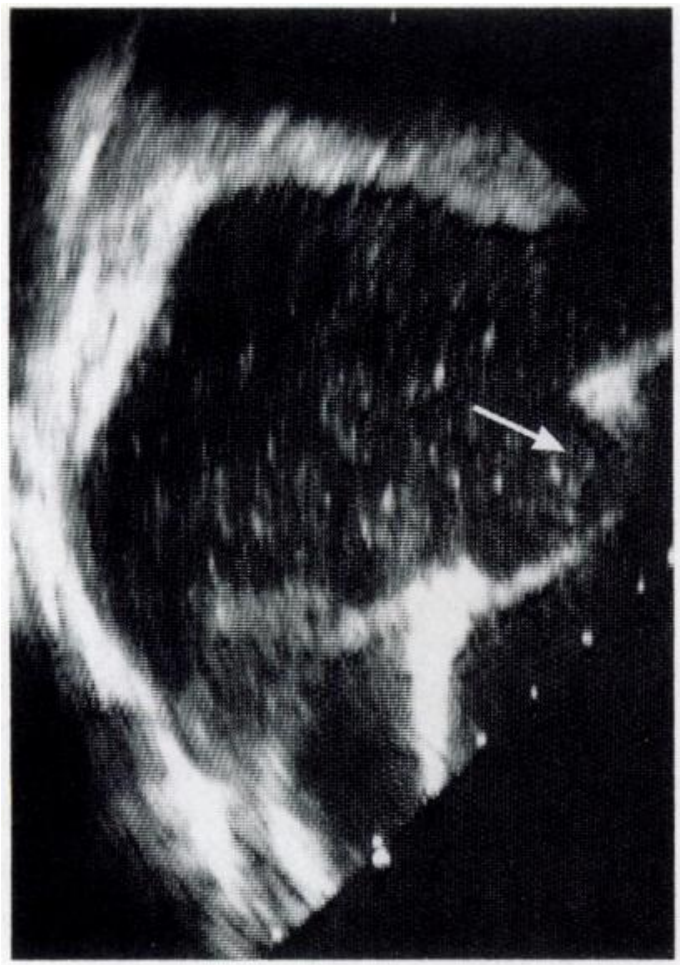

Fig. 1c

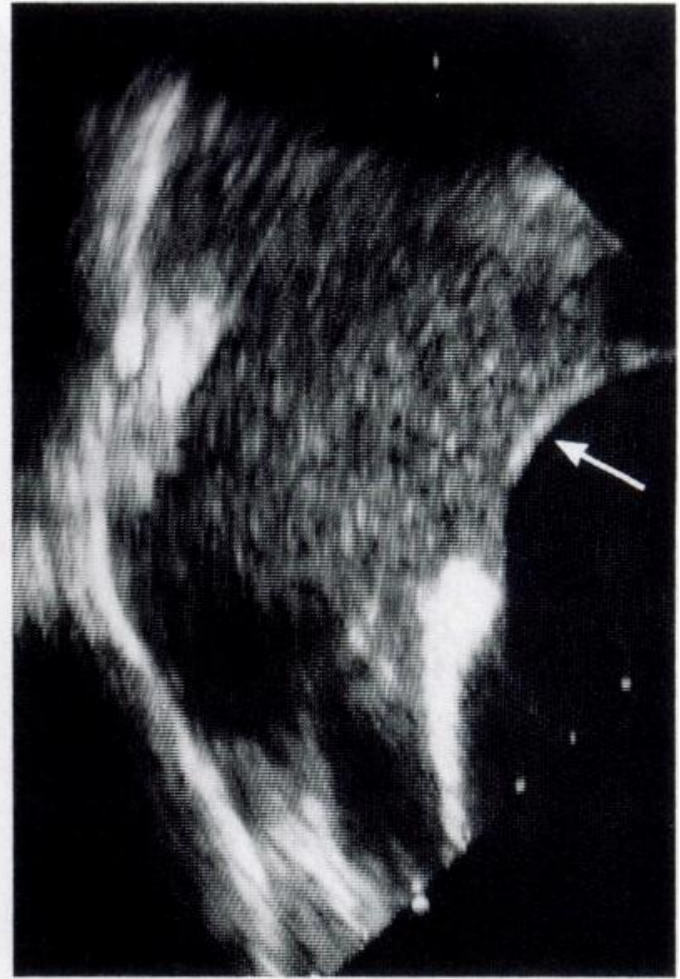

Fig. 1b

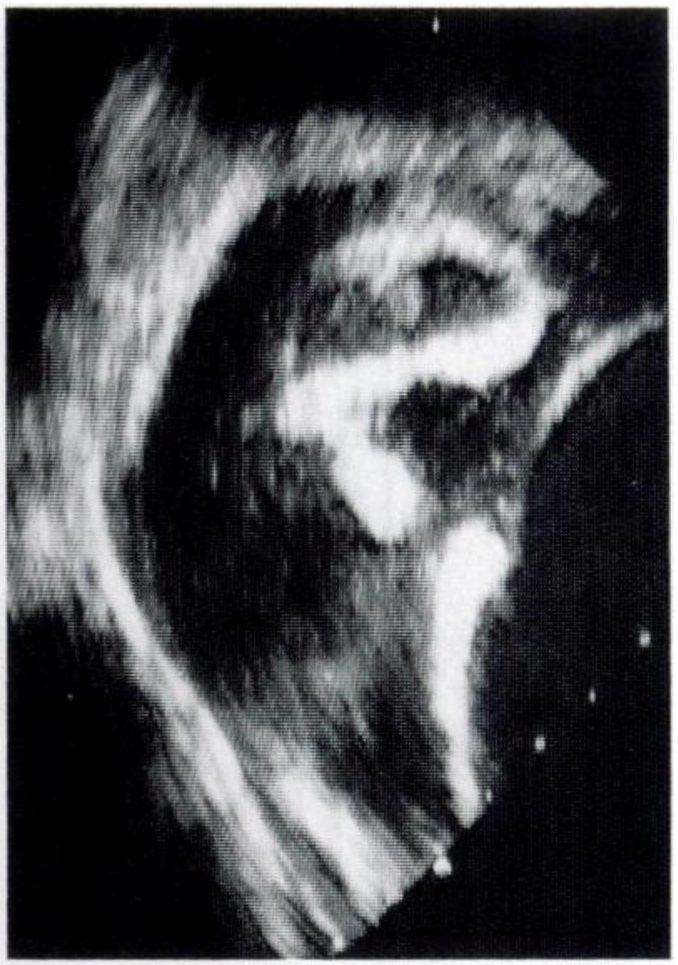

Fig. 1d

Right atrium during echocardiography. Figure 1a - The interatrial septum bulges towards the right atrium. Figure $1 \mathrm{~b}-$ Grade-II embolic cascade. Figure 1c - The bulge of the atrial septum is reversed. Figure 1d - A large embolus $7 \mathrm{~cm}$ in length, which is probably a cast of the femoral vein. 
Grade III. A cascade of fine emboli mixed with emboli more than $1 \mathrm{~cm}$ in diameter.

Grade IV. Large embolic masses more than $3 \mathrm{~cm}$ in diameter (Fig. 1d).

Table I shows the echogenic patterns in the two groups of patients. The cemented group had more severe and more prolonged thromboembolism than the uncemented group. The emboli occurred during the insertion of cement and continued during the insertion of the femoral component.

Patterns of embolic cascade. Embolic cascades were not seen (other than occasional mild grade-I responses) before surgery or during preoperative manipulation or formal massaging of the injured or the uninjured leg. In most patients proximal femoral reaming produced only minor transatrial cascades. In two patients, however, reaming resulted in a substantial grade-II and brief grade-III response. During the insertion of an uncemented femoral component there was usually little transatrial embolisation although in one patient there was a brief period of a gradeII and in another a transient grade-III response.

During cement insertion major transatrial cascades developed in eight of the ten patients. Four had emboli greater than grade III. Cascading continued and in some patients increased during insertion of the femoral component into the cement after which it continued for up to 15 minutes in four patients. Manipulation of the limb, reduction of the prosthesis and massaging of the leg after closure of the wound produced a short-lived but major embolic cascade in 10 patients. This phenomenon occurred mainly but not exclusively when there had been significant cascading beforehand.

The embolic cascades developed in a relatively predictable fashion. The first transatrial emboli were usually of fine echogenic material and progressed rapidly to a grade-II response. When this was prolonged, there was usually superimposition of a grade-III response.

Haematology. Eight patients agreed to have central catheters inserted. In four of the five patients with gradeII cascades, Gurd's test showed the presence of fat in the blood taken from the right atrium. Samples taken when there was no echogenic response contained no fat.

In one patient the atrial blood contained marrow constituents and there was marked platelet clumping in another. Echogenic material was seen in both of these patients. The catheters used to aspirate blood from the right atrium were not large enough to admit the grade-III emboli seen traversing the right atrium and we do not therefore know their composition.

Associated phenomena. We often saw the interatrial septum bulging towards the right atrium (Fig. 1a) indicating that pressure was higher in the left atrium than in the right. In two patients during major embolic cascades, the septum was seen to reverse its normal inclination and bulge towards the left (Fig. 1c), suggesting pulmonary hypertension and increased right atrial pressure.
Table I. Echogenic patterns in patients with cemented (Hastings) and uncemented (Austin-Moore) prostheses

\begin{tabular}{lllll}
\hline \multirow{5}{*}{ Prosthesis } & Grade III or IV & Grade II or III & Grade I or II & None \\
\cline { 2 - 5 } Hastings & 5 & 1 & 3 & 1 \\
Austin-Moore & 0 & 2 & 3 & 5 \\
\hline
\end{tabular}

$p=0.02$ (two-tailed test an exact test for trend)

see text

In some patients, after major embolic cascades, the end-tidal $\mathrm{CO}_{2}$ levels were decreased, with reduced $\mathrm{PaO}_{2}$ and $\mathrm{SaO}_{2}$. These results, however, were not sufficiently systematic to allow analysis.

Nature of the embolic cascades. It seems probable from our investigations that the initial grade-I and grade-II embolic cascades consisted of fine fat and marrow and possibly also of air. Grade-II cascades usually proceeded to grade-III and we assume that the larger particles visible during the latter were vein casts or fibrin and marrow aggregates resulting from rapid local intravenous clotting. Figure 1d illustrates this and shows a large snake-like embolus approximately $1 \mathrm{~cm}$ across and $7 \mathrm{~cm}$ long which appeared in the right atrium after reduction of a cemented implant. It arrested against the atrial catheter and postoperative attempts to remove it with venous baskets failed as it broke up and dispersed. Subsequent ventilationperfusion scans showed no obstruction to the pulmonary circulation. This large embolus may have been a cast of the femoral or profunda femoris veins.

\section{DISCUSSION}

Echocardiography gives a remarkable insight into thromboembolic phenomena during medullary instrumentation and implantation. Extensive transatrial cascades may occur during medullary reaming (Pell et al 1993b) but we do not yet have an adequate explanation for their quantitative variation. Our study showed that the insertion of a femoral component with cement is associated with more prolonged and more severe transatrial embolism than if no cement is used.

In some of the patients in whom major embolic events were observed there was transient hypoxaemia, pulmonary hypertension and decreased end-tidal $\mathrm{CO}_{2}$ levels. It is tempting to conclude that these phenomena were a direct consequence of the embolic cascades, but other mechanisms may also have been involved, including cement toxicity (Peebles et al 1972; Mir, Lawrence and Autian 1973), reflex autonomic effects (Rudigier and Ritter 1983) and prostaglandin-induced vasodilatation (Byrick et al 1991). Nevertheless, we assume that the extensive and prolonged embolic events that occur particularly during the insertion of the cement must cause substantial although usually transient pulmonary impairment and possibly also some of the other adverse clinical events that have been reported during hip replacement. 
Marrow and fat emboli have previously been implicated in producing hypotension during cement insertion (Sevitt 1972; Breed 1974; Byrick et al 1987). Echocardiography confirmed that major embolic events occur during cement insertion and further showed that there is a graduated response with progression from an initial fine embolic cascade to a mixed cascade with larger echogenic masses which may measure more than $1 \mathrm{~cm}$ in length. We think that these larger masses probably consist of fat, marrow and fibrin which have accumulated in the leg veins after extrusion of marrow parenchyma. They may result from a rapidly developing local thromboembolic disorder stimulated by the local release into the veins of tissue-breakdown products and clotting factors.

A rapidly developing and incremental response of this kind would certainly explain the appearances that we have observed during echocardiography and might well also explain why a relatively small quantity of extruded fat and marrow from the proximal femoral canal may sometimes give rise to serious clinical events. Fibrinolytic and lipolytic enzymes within the pulmonary circulation may diminish the effects of the pulmonary insult and explain the transient nature of the clinical signs. Further experimental work will be required to confirm this sequence of events.

Conclusions. We have shown that femoral hemiarthroplasty with cement fixation is associated with more frequent and more extensive thromboembolic cascades than if cement is not used. These emboli may be the consequence of a local thromboembolic disorder and may cause pulmonary hypertension and impaired gas exchange.

No benefits in any form have been received or will be received from a commercial party related directly or indirectly to the subject of this article.

\section{REFERENCES}

Breed AL. Experimental production of vascular hypotension, and bone marrow and fat embolism with methylmethacrylate cement: traumatic hypertension of bone. Clin Orthop 1974; 102:227-44.

Burgess DM. Cardiac arrest and bone cement (letter). Br Med J 1970; 3:588.

Byrick RJ, Kay JC, Mullen JBM. Pulmonary marrow embolism: a dog model simulating dual component cemented arthroplasty. Can J Anaesth 1987; 34:336-42.
Byrick RJ, Mullen JB, Wong PY, et al. Prostanoid production and pulmonary hypertension after fat embolism are not modified by methylprednisolone. Can J Anaesth 1991; 38:660-7.

Charnley J. Acrylic cement in orthopaedic surgery. Edinburgh, etc: E \& S Livingstone, 1970.

Gurd AR. Fat embolism: an aid to diagnosis. J Bone Joint Surg [Br] 1970; 52-B:732-7.

Heinrich H, Kremer P, Winter H, Wörsdorfer O, Ahnefeld FW. Transoseophageale zweidimensionale Echokardiographie bei Hüftendoprosthesen. Anaesthesist 1985; 34:118-23.

Heinrich $\mathbf{H}$, Kremer $\mathbf{P}$, Winter $\mathbf{H}$, et al. Embolic events during total hip replacement: an echocardiographic study. Acta Orthop Belg 1988; 54:12-7.

Jones RH. Physiologic emboli changes observed during total hip replacement arthroplasty: a clinical prospective trial. Clin Orthop $1975 ; 112: 192-200$.

Kallos T. Impaired arterial oxygenation associated with use of bone cement in the femoral shaft. Anesthesiology 1975; 42:210-6.

Mir GN, Lawrence WH, Autian J. Toxicological and pharmacological actions of methylmethacrylate monomers. I. Effects on isolated perfused rabbit heart. J Pharm Sci 1973; 62:778-82.

Parmet JL, Berman AT, Horrow JC, Harding S, Rosenberg H. Thrombo-embolism coincident with tourniquet deflation during total knee arthroplasty. Lancet 1993; 341:1057-8.

Peebles DJ, Ellis RH, Stride SDK, Simpson BRJ. Cardiovascular effects of methylmethacrylate cement. Br Med J 1972; 1:349-51.

Pell ACH, Christie J, Keating JF, Sutherland GR. The detection of fat embolism by transoesophageal echocardiography during reamed intramedullary nailing: a study of 24 patients with femoral and tibial fractures. J Bone Joint Surg [Br] 1993a; 75-B:921-5.

Pell AC, Hughes D, Keating J, et al. Fulminating fat embolism syndrome caused by paradoxical embolism through a patent foramen ovale. N Engl J Med 1993b; 329:926-9.

Ries MD, Lynch F, Rauscher LA, et al. Pulmonary function during and after total hip replacement: findings in patients who have insertion of a femoral component with and without cement. J Bone Joint Surg [Am] 1993; 75-A:581-7.

Rudigier JF, Ritter G. Pathogenesis of circulatory reactions triggered by nervous reflexes during the implantation of bone cements. Res Exp Med (Berl) 1983; 183:77-94.

Samii K, Elmelik E, Goutalier D, Viars P. Hemodynamic effects of prosthesis insertion during knee replacement without tourniquet. Anesthesiology 1980; 52:271-3.

Sevitt S. Fat embolism in patients with fractured hips. Br Med J 1972 2:257-62.

Wenda K, Henrichs KJ, Biegler M, Erbel R. Nachweis von markembolien während oberschenkelmarknagelungen mittels transösophagealer echokardiographie. Unfallchirurgie 1989; 15:73-6.

Wheelwright EF, Byrick RJ, Wigglesworth DF, et al. Hypotension during cemented arthroplasty: relationship to cardiac output and fat embolism. J Bone Joint Surg [Br] 1993; 75-B:715-23. 